Revista de Educação e Pesquisa em Contabilidade Journal of Education and Research in Accounting

Revista de Educación e Investigatión en Contabilidad
REPeC, Brasília, v.6, n. 2, art. 3, p. 154-169, abr./jun. 2012 Disponível online em www.repec.org.br

\title{
Distribuição de Dividendos e de Juros Sobre o Capital Próprio Versus Retorno das Ações
}

\author{
Renato Marques Corso \\ Bacharel em Ciências Contábeis (FEA-USP) \\ Endereço: Rua Apotribu, 150, Apto 41 A, Parque Imperial, São Paulo/SP, CEP 04.302-000 \\ E-mail: renato.corso@gmail.com
}

\section{José Roberto Kassai}

Doutor em controladoria e contabilidde (FEA-USP)

Professor da FEA/USP e Coordenador do NECMA/USP

Enereço: Av. Prof. Luciano Gualberto 908, Cidade Universitária, São Paulo/SP, CEP 05.508-900

E-mail:jrkassai@usp.br

\section{Gerlando Augusto Franco Sampaio Lima}

Professor Doutor da Universidade de São Paulo

Pós-Doutor em Economia pela Universidade de Coimbra, Doutor e Mestre em Controladoria e Contabilidade pela FEA/USP. Enereço: Av. Prof. Luciano Gualberto 908, Cidade Universitária, São Paulo/SP, CEP 05.508-900

E-mail: gerlando@usp.br

\section{Resumo}

Este estudo tem como objetivo investigar a relação entre a distribuição de dividendos e de juros sobre o capital próprio com o retorno das ações. Tem-se, como referencial teórico deste estudo, a Teoria da Irrelevância dos Dividendos de Miller \& Modigliani (M\&M, 1961) e a Teoria do Pássaro na Mão de Gordon \& Lintner (1963) conforme Brigham, Gapenski, e Ehrhardt (2001), além da apresentação de pesquisas nacionais sobre o assunto. Do ponto de vista de seus objetivos, esta pesquisa classifica-se como descritiva e será utilizada a abordagem empírico-analítica para o tratamento dos dados. Os dados para análise foram coletados a partir do software Economática, sendo a amostra representada por empresas com ações negociadas na Bolsa de Valores de São Paulo (BM\&FBovespa), e o período analisado compreende os anos de 1995 a 2008. Antes de analisar a regressão com dados em painel, foi utilizada a técnica multivariada de análise de correspondência (Anacor) para se fazer uma análise exploratória das variáveis estudadas. Os resultados indicaram que existe relação entre distribuição de dividendos e de juros sobre o capital próprio com o retorno das ações, dessa forma, não se rejeitou a hipótese estudada. A partir da utilização da regressão com efeitos fixos, pelo método dos mínimos quadrados ordinários, cujo R Quadrado foi de aproximadamente $47,55 \%$, verificou-se que a distribuição de dividendos e juros sobre o capital próprio apresenta relação inversa com o retorno das ações. Espera-se com esta pesquisa fornecer e ampliar as evidências empíricas a respeito do assunto e oferecer subsídios para futuras pesquisas.

Palavras-Chave: Dividendos; Retorno; ANACOR; Regressão; Dados em Painel.

\section{Editado em Português, Inglês e Espanhol. Versão original em Português.}

Recebido em 28/09/10. Pedido de Revisão em 13/01/11. Resubmetido em 28/02/11. Aceito em 28/10/2011 por Valcemiro Nossa (Editor). Publicado em 28/06/12. Organização responsável pelo periódico: CFC/FBC/ABRACICON.

Copyright (C) 2012 REPEC. Todos os direitos, até mesmo de tradução, são reservados. É permitido citar parte de artigos sem autorização prévia, desde que seja identificada a fonte. 


\section{repec}

\section{INTRODUÇÃO}

A política de dividendos é um tema em Finanças Corporativas que vem sendo objeto de estudo há várias décadas. Diversas teorias e estudos empíricos sobre os possíveis efeitos da política de dividendos no valor da empresa e retorno das ações foram elaborados. Dentre as teorias, destacam-se as correntes de pensamento clássicas: a Teoria da Irrelevância dos Dividendos de Miller \& Modigliani (M\&M, 1961) e a Teoria do Pássaro na Mão de Gordon \& Lintner (1963).

Segundo Brigham, Gapenski, e Ehrhardt (2001), a política de dividendos envolve a decisão de distribuição dos lucros versus a retenção deles para reinvestimento na empresa. A política de dividendos ótima faz um balanço entre os dividendos correntes e o crescimento futuro a fim de maximizar o preço da ação da empresa. A política de dividendos, conforme Brigham, Gapenski, e Ehrhardt (2001, p. 662)

envolve três assuntos: (1) qual fração dos lucros, em média, deve ser distribuída ao longo do tempo?; (2) a distribuição deve ser na forma de dividendos em moeda corrente, ou como recompra de ações?; (3) a empresa deve manter uma taxa de crescimento firme e estável?

O mercado de ações tem uma importante participação no processo de desenvolvimento das sociedades e os participantes do mercado acionário visam obter seus rendimentos por meio do ganho de capital quando da compra e venda das ações ou sob a forma de recebimento de dividendos e juros sobre capital próprio (o último restrito ao Brasil).

Na legislação brasileira, a distribuição de dividendos consta da Lei n. ${ }^{\circ} 11.638$, de 28 de dezembro de 2007, e na Lei n. ${ }^{\circ} 10.303$, de 31 de outubro de 2001, que altera dispositivo da Lei ${ }^{\circ}{ }^{\circ} 6.404$ e regulamentos específicos da Comissão de Valores Mobiliários (CVM). Estabelece um dividendo mínimo obrigatório de $25 \%$ sobre o lucro líquido ajustado, exceto se o estatuto da empresa estabelecer outra condição.

No Brasil, a partir de 1996, um novo mecanismo de pagamento de dividendos foi criado sob a forma de juros sobre o capital próprio, classificado contabilmente como despesa dedutível da base de cálculo do imposto de rendada pessoa jurídica, gerando, por conseguinte, um benefício físcal à empresa pagadora. O montante pago na forma de juros sobre o capital próprio pode ser imputado aos dividendos e ser pago, assim como este, em dinheiro. Dessa maneira, nesta pesquisa essas duas formas de remuneração dos acionistas são tratadas, estudando-se o total do pagamento de proventos em dinheiro.

Segundo Bruni et al. (2003), nos Estados Unidos, mercado que contém uma das principais bolsas de valores do mundo, os dividendos são tributados, assim como os ganhos de capital. Por outro lado, no Brasil, o ganho de capital é tributado em $20 \%$, os dividendos são isentos de tributação e os juros sobre capital próprio são tributados na fonte. Tal fato sugere a relevância da política de dividendos.

Conforme Nossa, Nossa e Teixeira $(2007$, p.3)

A tributação incidente sobre dividendos e ganhos de capitais também deve influenciar na determinação dos dividendos. O retorno sobre o investimento em uma empresa pode se dar através do pagamento de dividendos e aumento no valor das ações no mercado, sendo mais importante para o acionista a alternativa que lhe produza a melhor rentabilidade líquida após a tributação. Desta forma, a decisão do pagamento dos dividendos deve levar em consideração a forma que maximiza o retorno dos acionistas.

Segundo Assaf Neto (2003, p.429), no Brasil os pontos sobre as políticas de dividendos são colocados em nível de grande desprezo pelas empresas, de pouco uso pelos investidores em geral e oferecem à comunidade acadêmica, ainda, poucos trabalhos conclusivos sobre a matéria. Alia-se, ainda, a legislação vigente no Brasil que estabelece o pagamento de um dividendo mínimo obrigatório, não permitindo que essa decisão flua livremente por meio de decisões da administração da empresa e de seus acionistas. 


\section{repec}

O tema política de dividendos e seus efeitos no valor da empresa e retorno de ações é bastante controverso. Muitos dos estudos realizados em contabilidade e finanças têm sido direcionados à mudança da política dos dividendos adotada pelas organizações. Diversos são os enfoques dados nos estudos e geralmente as investigações apresentadas na literatura buscam relacionar a distribuição de dividendos aos lucros anormais das empresas e a relação entre dividend yields e retorno das ações.

Esse é um assunto de interesse de vários usuários, como afirma Bueno (2000, p.10):

A possibilidade de se investir em ações com base em estratégias de dividendos é de interesse não apenas acadêmico, mas também profissional. Além de constituírem objeto de estudo de Finanças, Contabilidade e Controladoria, Economia e Direito, fazem parte do interesse de profissionais como os administradores de carteiras, os investidores institucionais, os analistas de investimentos, órgãos reguladores e fiscalizadores do mercado de capitais, etc.

Com o propósito de se obter maior clareza sobre este tema, o objetivo desta pesquisa é buscar evidências empíricas da relação entre a distribuição de dividendos e de juros sobre capital próprio com a valorização do preço das ações. Espera-se com esta pesquisa contribuir com o fornecimento de evidências empíricas a respeito do assunto, ampliar os conhecimentos acerca do tema política de dividendos e oferecer subsídios para futuras pesquisas.

Este estudo tem como objetivo principal investigar a relação entre a distribuição de dividendos e de juros sobre o capital próprio com o retorno das ações das empresas listadas na Bolsa de Valores de São Paulo (Bovespa). Na busca de evidências empíricas para responder ao problema-pesquisa, testa-se a seguinte hipótese:

$\mathbf{H}_{\mathbf{0}}$ : Existe relação entre a distribuição de dividendos e de juros sobre o capital próprio com o retorno das ações.

Constituem-se nos objetivos específicos deste trabalho:

- $\quad$ analisar a relação das variáveis retorno das ações e distribuição de dividendos e de juros sobre capital próprio;

- $\quad$ avaliar a evolução do retorno das ações e da distribuição de dividendos e de juros sobre capital próprio.

- $\quad$ investigar a dependência entre a variável retorno das ações e a variável distribuição de dividendos e de juros sobre capital próprio.

Uma breve revisão da literatura, abordando as principais teorias relacionadas à política de dividendos, e alguns estudos importantes realizados por meio de levantamento bibliográfico serão apresentados a seguir. Posteriormente, descreve-se a metodologia, bem como ela será aplicada. Em seguida, são apresentados os resultados obtidos, bem como suas análises. E, finalmente, são apresentadas as conclusões da pesquisa.

\section{REVISÃO BIBLIOGRÁFICA}

Partindo do pressuposto de que os administradores financeiros devem sempre ter em mente que o objetivo da empresa é o de maximizar o valor para os acionistas. Consequentemente surge uma questão sobre a preferência dos investidores: os investidores preferem obter o retorno pela distribuição de dividendos e de juros sobre o capital próprio, ou sobre ganhos de capital?

Segundo Brigham, Gapenski e Ehrhardt (2001, p. 640) 


\section{repece}

os investidores não podem ser vistos como preferindo uniformemente dividendos mais altos ou mais baixos. Contudo, os investidores individuais têm fortes preferências. Alguns preferem altos dividendos, enquanto outros preferem tudo em ganho de capital. Essas diferenças entre os indivíduos ajudam a explicar por que é difícil alcançar quaisquer conclusões definitivas sobre a distribuição de dividendos ótima.

Para responder a esta questão da preferência dos investidores por dividendos e juros sobre o capital próprio versus ganhos de capital é importante entender as três teorias de preferência que explicam a preferência do investidor: Teoria da Irrelevância dos Dividendos, a Teoria do Pássaro na Mão e a Teoria da Preferência Tributária.

Os proponentes principais da Teoria da Irrelevância dos Dividendos são Miller e Modigliani. Segundo Brigham, Gapenski e Ehrhardt (2001, p. 637),

Eles afirmaram que o valor da empresa é determinado somente por sua capacidade de geração de lucro e pelo risco do negócio. Em outras palavras, Merton Miller e Franco Modigliani defenderam que o valor da empresa depende somente do lucro produzido por seus ativos e não de como esse lucro é dividido entre dividendos e lucros acumulados.

Ao desenvolver sua teoria de dividendos, Miller e Modigliani fizeram várias suposições. Conforme Bueno (2000, p. 45),

As hipóteses básicas são:

a) o mercado é perfeito, isto é, nenhum agente é capaz de afetar a cotação com compras ou vendas;

b) não existem impostos ou corretagem;

c) o comportamento dos agentes são racionais e homogêneos (idênticas);

d) os investimentos são definidos de antemão e não se alteram por mudanças na política de dividendos.

Segundo Bruni et al. (2003 p. 4), "ao considerar imperfeições no mercado, como, por exemplo, assimetrias de informação, impostos, custos de transação e conflitos de interesses entre administradores e acionistas, as controvérsias aparecem".

Dessa forma, surge o efeito do conteúdo informacional dos dividendos (sinalização) e o efeito clientela. Conforme Santana (2006 p. 27),

II) Caso os dividendos afetem o valor da empresa, isso ocorre apenas devido ao Conteúdo Informacional (Sinalização) que revela as expectativas dos administradores das empresas. Pois, não seria a preferência dos acionistas correntes que levaria a acréscimos nos preços das ações e sim a expectativa de ganhos futuros, esperada a partir da retenção de lucros. III) Ocorre um Efeito Clientela, que leva os acionistas a receberem os dividendos que eles próprios esperam. Pois, investidores que preferissem investimentos estáveis e previsíveis como fonte de renda, deteriam de ações que pagassem o mesmo montante a títulos de dividendos a cada período. Enquanto que, aqueles investidores que preferissem ganhos de capital seriam atraídos preferencialmente por empresas em fase de crescimento que reinvestissem uma grande parcela de seus lucros e, portanto, revelassem um padrão instável no pagamento dos dividendos.

Assim, a política de dividendos deve levar em consideração o conteúdo informacional dos dividendos (sinalização), e o efeito clientela, segundo Brigham, Gapenski e Ehrhardt (2001, p. 663), diz: 


\section{repec}

O efeito do conteúdo informacional, ou sinalização, refere-se ao fato de que os investidores relacionam uma mudança inesperada de dividendos como um sinal de previsão da administração dos lucros futuros. O efeito clientela sugere que uma empresa atrairá investidores que concordem com a política de distribuição de dividendos da empresa. Ambos os fatores devem ser considerados pelas empresas que estão cogitando uma mudança na política de dividendos.

Dessa forma, as expectativas em relação aos fluxos de caixas futuros são bem observadas pelo mercado financeiro, além dos investimentos que as empresas planejam para o futuro. Quando uma empresa anuncia mudanças na política de dividendos, ela transmite uma informação ao mercado, que as assimila refletindo nos preços das ações. Segundo Bruni et al. (2003), essas informações podem ser de dividendos como sinal positivo e de dividendos como sinal negativo.

Dividendos como um sinal positivo, para Bruni et al. (2003, p. 5),

indica que empresas com bons projetos precisam tomar medidas que não possam ser facilmente imitadas pelas empresas sem bons projetos. Aumentar dividendos pode ser visto como uma ação desta natureza. Ao aumentar os dividendos, elas estariam criando um custo para si mesmas, aumentando necessidades de fluxo de caixa ao longo prazo. $\mathrm{O}$ fato de que estão dispostas a assumir este compromisso indica aos investidores que elas acreditam que têm a capacidade de gerar estes fluxos de caixa. O mercado assimila este sinal de forma positiva, levando a uma reavaliação dos valores da empresa e a um aumento no preço das ações.

Ainda segundo Bruni et al. (2003, p. 6), dividendos como um sinal negativo é:

Aumento nos dividendos, de outra parte, pode enviar um sinal negativo para os mercados financeiros. Ao considerar uma empresa que nunca pagou dividendos no passado, mas que registrou um crescimento extraordinário e alto retorno sobre seus projetos. Quando esta empresa começar a pagar ou aumentar substancialmente os dividendos, seus acionistas podem considerar isto como um indicativo de que os projetos da empresa não são tão lucrativos como costumavam ser. Neste caso a reavaliação dos preços das ações ocorrerá de forma negativa.

Pela ótica do mundo ideal de Miller e Modigliani, o efeito clientela é visto da seguinte forma: uma empresa que paga o mesmo montante de dividendos atrai investidores interessados em fluxos estáveis de caixa. Por outro lado, investidores interessados em ganhos de capital são atraídos por empresas que reinvestem seus lucros (BRUNI et al., 2003, p. 6).

Pode-se destacar ainda um cenário em que o investidor não tem projeto para destinar os dividendos, conforme Nossa, Nossa, e Teixeira (2007). Assim o investidor iria buscar ações de empresas que reinvistam os lucros e gerem ainda mais recursos para os acionistas em longo prazo.

Contrários à Teoria da Irrelevância dos Dividendos, Gordon e Lintner defenderam a relevância dos dividendos. Para Brigham, Gapenski e Ehrhardt (2001, p. 662), a "Teoria do Pássaro na Mão defende que o valor da empresa será maximizado por um alto índice de distribuição de dividendos, porque os dividendos em moeda corrente são menos arriscados do que os potenciais ganhos de capital".

A proposição fundamental dessa teoria, segundo Santana (2006 p. 27),

é o argumento do "Pássaro na Mão" que sugere que os investidores são avessos ao risco e preferem dividendos correntes a dividendos futuros ou ganhos de capital (pois, mais vale um dividendo na mão do que um ganho de capital incerto). Acredita-se que 
os pagamentos de dividendos correntes reduzam a incerteza dos investidores, elevando conseqüentemente o preço das ações. De outra forma, se os dividendos forem reduzidos ou não pagos, a incerteza dos investidores aumentaria, assim como o retorno exigido, tendo como conseqüência à queda no preço das ações.

Outra teoria desenvolvida, que envolve a decisão da política de dividendos é a Teoria da Preferência Tributária, citada por Brigham, Gapenski e Ehrhardt (2001, p. 662) "em virtude de os ganhos de capital de longo prazo estarem sujeitos a impostos menos onerosos do que os dividendos, os investidores preferem que as empresas retenham lucros em lugar de distribuí-los como dividendos".

Essa teoria destina-se a explicar o efeito da tributação diferenciada sobre a política de dividendos. Argumenta-se que, havendo taxação de impostos sobre os ganhos de capital e os dividendos, de forma diferenciada, os acionistas tenderiam a escolher a opção que lhe trouxesse menos encargos tributários. Segundo Bueno (2000, p. 49),

mesmo quando as alíquotas fossem idênticas, haveria ainda o benefício do desembolso, pois, enquanto os impostos sobre dividendos são pagos no momento de seu recebimento, nos ganhos de capital paga-se apenas quando o lucro é realizado, ou seja, quando as ações são vendidas. (2007, p. 3),

O efeito clientela também é influenciado pela tributação. Conforme Nossa, Nossa, e Teixeira investidores altamente tributados não teriam interesse na distribuição de dividendos. Enquanto que aqueles acionistas relativamente pouco tributados seriam induzidos ao efeito "clientela". Diante disto, para atender a investidores com interesses diferenciados, o mercado acionário teria empresas que distribuem dividendos e aquelas que não o fazem.

O Gráfico a seguir representa as três teorias alternativas de política de dividendos: a Teoria da Irrelevância dos Dividendos, a Teoria do Pássaro na Mão e a Teoria da Preferência Tributária, esta última, supondo-se que os dividendos são tributados a alíquotas maiores do que do ganho de capital.

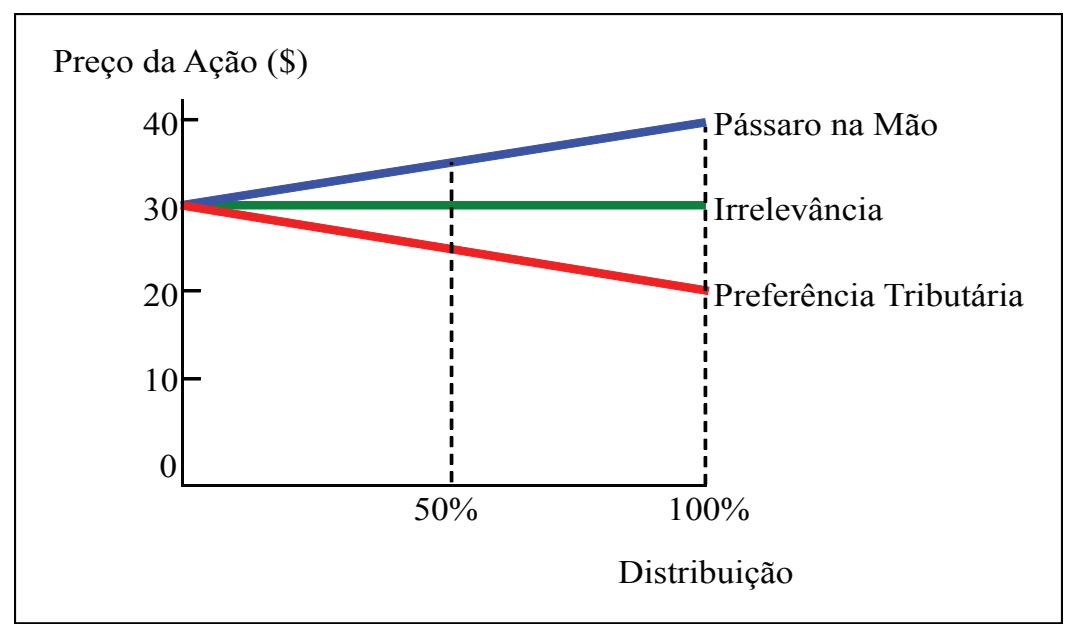

Gráfico 1: Ilustração das Três Teorias de Políticas de Dividendos

Fonte: Adaptado de Brigham, Gapenski e Ehrhardt (2001, p. 639) 


\section{repec}

Ao longo dos últimos 50 anos, nos Estados Unidos, diversos estudos foram realizados, destacando-se várias conclusões interessantes. Segundo Bruni et al. (2003, p.2),

os dividendos tendem a seguir as receitas; isto é, aumentos nas receitas são seguidos por aumentos nos dividendos e quedas nas receitas por cortes nos dividendos. Segundo, as empresas são caracteristicamente relutantes em alterar sua política de dividendos; esta indecisão cresce quando chega o momento de cortarem dividendos levando a políticas de dividendos "amarrados". Terceiro, os dividendos tendem a seguir uma rota muito mais uniforme do que os lucros. Finalmente, há políticas de dividendos ao longo do ciclo de vida de uma empresa, resultantes da variação das taxas de crescimento, dos fluxos de caixa e da disponibilidade de projetos.

No Brasil, diversos autores apresentaram estudos sobre a relevância dos dividendos. Alguns dos principais trabalhos estão apresentados a seguir.

Lima e Paiva (2001) analisaram evidências empíricas a respeito da influência da tributação e dos juros sobre o capital próprio na política de dividendos nas empresas no período entre 1995 a 1998, através do estudo do comportamento dos níveis de distribuição de dividendos das empresas brasileiras. Os resultados indicaram que as empresas não aumentaram o índice payout depois da eliminação da tributação sobre os dividendos. Muitas empresas não registraram os juros sobre capital próprio, mas sua adoção vem crescendo ao longo dos anos. As empresas que pagaram juros sobre capital próprio apresentaram tendência de elevação do payout e aumento efetivo dos dividendos. Entretanto, a maioria das empresas não distribuiu integralmente o benefício fiscal aos seus acionistas.

Bueno (2000) analisou a relação entre dividend yield e as taxas de retorno das ações brasileiras, no período entre junho de 1994 a dezembro de 1999, bem como a viabilidade de uma estratégia baseada em dividend yield. Construiu três diferentes carteiras: alto, baixo e zero dividend yield. Os resultados obtidos foram incapazes de concluir que as ações de alto dividend yield tendem a possuir maiores ou menores taxas de retorno do que as ações de baixo ou zero yield. As evidências também sugerem que não é possível demonstrar, usando o método empírico aplicado, uma clara associação entre dividend yield e taxa de retorno das ações.

Correia e Amaral (2002) analisaram a existência de efeito da política de distribuição de resultados de empresas brasileiras sobre o valor de mercado das suas ações, ou seja, verificar se o retorno das ações pode ser explicado não apenas pelo fator de risco sistemático, como pressupõe o modelo Capital Assets Pricing Models (CAPM), mas também pela variável de rendimento em dividendos. Os resultados mostraram que tanto o risco sistemático quanto os rendimentos em dividendos são fatores que explicam a rentabilidade de mercado de ações, consequentemente, a política de dividendos adotada pelas empresas brasileiras analisadas neste estudo, cujas ações foram negociadas na Bovespa, no período de 1994 a 2000 , causa impacto sobre os seus valores de mercado.

Novis Neto e Saito (2002) analisaram empiricamente o comportamento dos preços das ações após o anúncio do pagamento dos dividendos das ações negociadas na Bovespa no período de 1998 a 2000. Encontraram uma relação direta entre o dividend yield e o retorno anormal acumulado no período pós-pagamento dos dividendos, dividindo a amostra em três subamostras em função do dividend yield. Obtiveram um retorno anormal acumulado nos 90 dias após o evento de $21,97 \%$ para empresas que pagaram maiores dividendos e 5,16\% para as que pagaram dividendos intermediários, e $15,50 \%$ para as que pagaram dividendos mais baixos, demonstrando assim persistência de retornos anormais no período pós-evento.

Bruni et al. (2003) analisaram o efeito do anúncio da distribuição de dividendos ou juros sobre capital próprio sobre os preços de uma amostra de ações negociadas na Bovespa. Os resultados não permitiram evidenciar nenhum resultado significativo. É possível estabelecer que ou o mercado antecipa informação do anúncio de dividendos ou esta informação não é relevante. Por outro lado, os resultados evidenciaram a presença de retornos anormais sistematicamente positivos na amostra total. Assim, deduz-se 
que ações com dividend yield acima da mediana apresentam uma valorização superior, indicando a preferência pelos investidores por ações com políticas mais agressivas de distribuição dos dividendos.

Heineberg e Procianoy (2003) buscaram testar a influência de aspectos teóricos que poderiam ser determinantes na formação do valor distribuído na política de proventos das empresas brasileiras negociadas na Bovespa durante os anos de 1994 a 2000. Nesta pesquisa é possível notar que, embora algumas relações teóricas esperadas não tenham sido encontradas com significância estatística, a política de distribuição de proventos nas empresas de capital aberto apresenta consistência e uma boa estabilidade no que tange à constância e previsibilidade dos valores pagos aos acionistas. Assim, esta pesquisa consegue apresentar um padrão consistente de comportamento da política de distribuição de proventos em dinheiro das empresas brasileiras.

Lima e Freire (2003) buscaram evidenciar a relação entre os dividendos yield e os lucros anormais. Verificou-se, entretanto, a não existência de relação entre o dividendo yield e o lucro anormal, rejeitando-se assim a hipótese nula $\left(\mathrm{H}_{0}\right)$.

Santana (2006) verificou quais os fatores que determinam a política de dividendos, considerando a oportunidade de crescimento e investimento da empresa, o setor de atividade e a capacidade de geração de lucros da empresa. Verifica-se que somente este último, representado pelo índice ROA (return on assets), é que está relacionado com os dividendos. A decisão da política de dividendos é influenciada por vários contextos que refletem as características, situação e estratégias financeiras da empresa. E, no caso do presente estudo, a lucratividade seria um fator importante a ser considerado para essa decisão. É encontrado resultado da regressão realizada entre o retorno das ações e dividend yield somente na característica do setor de atividade. A característica setorial referente a empresas de setores de consumo não cíclicos pode ser explicada, pois esse segmento de empresas normalmente é menos afetado por variações do ciclo econômico. E, como conseqüência, tais setores possuem uma maior tendência à distribuição dos dividendos se comparados às empresas de setores de consumo cíclico.

Nossa, Nossa, e Teixeira (2007) analisaram as empresas listadas na Bovespa, no intuito de verificar se as empresas que distribuíram dividendos no período de 1995 a 2004 são mais eficientes do que aquelas que não distribuíram dividendos. $\mathrm{O}$ resultado observado indica que as empresas que distribuem dividendos são mais eficientes do que as empresas que não distribuem dividendos, no período analisado, inclusive o dividendo distribuído está positivamente relacionado ao retorno sobre o ativo.

\section{METODOLOGIA}

Para responder ao problema-pesquisa, se existe relação entre a distribuição de dividendos e juros sobre capital próprio, com a valorização do preço das ações, será utilizada a abordagem empírico-analítica. As pesquisas do tipo empírico-analítica, segundo Martins (2000, p. 26),

são abordagens que apresentam em comum a utilização de técnicas de coleta, tratamento e análise de dados marcadamente quantitativos. Privilegiam estudos práticos. Suas propostas têm caráter técnico, restaurador e incrementalista. Têm forte preocupação com a relação causal entre as variáveis. A validação da prova científica é buscada através de testes dos instrumentos, graus de significância e sistematização das definições operacionais.

Do ponto de vista de seus objetivos, a pesquisa pode ser classificada como pesquisa descritiva, visto que o estudo destina-se a verificar a relação entre as variáveis distribuição de dividendos e de juros sobre o capital próprio e retorno das ações.

Com a finalidade de investigar a relação entre a distribuição de dividendos e de juros sobre o capital próprio com o retorno das ações, esta pesquisa será tratada sob o paradigma positivo. Lopes e Martins $(2005$, p. 4) afirmam que 


\section{repec}

muitos modelos foram desenvolvidos e técnicas econométricas e estatísticas foram utilizadas sob o paradigma positivo do estabelecimento de hipóteses, derivadas da teoria, seguidas do teste empírico das mesmas vistas à verificação e como a realidade se adequa ao estabelecido pela teoria (WATTS e ZIMMERMAN, 1986). A maior parte desses trabalhos tem sido realizada na tentativa de estudar o impacto da divulgação de informações contábeis no comportamento dos ativos em mercados financeiros (BROWN, 1996).

Para a elaboração desta pesquisa, serão selecionadas as ações das companhias abertas negociadas na Bovespa e o período que será analisado compreende os anos de 1995 a 2008. Este período foi escolhido devido à relativa estabilidade econômica após a criação do Plano Real. Dessa forma, chegou-se ao número de 1.119 ações analisadas. É importante ressaltar que nem sempre as ações foram negociadas, assim não tiveram preços estabelecidos em determinados anos e também nem sempre proventos foram distribuídos.

Os dados referentes às cotações dos preços das ações, bem como os dados acerca da distribuição de dividendos e de juros sobre o capital próprio foram obtidos no banco de dados do software de análise de investimento em ações Economática. As cotações utilizadas são ajustadas pelo software para que efeitos como desdobramentos e grupamentos de ações não provoquem a descontinuidade do preço das ações. Dessa forma, é possível calcular corretamente o retorno das ações, conforme a seguinte expressão:

$$
\text { Retorno }=\left(\frac{\text { Último Preço de Fechamento no Ano X }}{\text { Último Preço de Fechamento no Ano X - 1 }}-1\right) \times 100 \%
$$

Para analisar a distribuição de dividendos e de juros sobre o capital próprio das ações, foi utilizada a variável Dividend Yield do software, que pode ser expressa através da seguinte expressão:

$$
\text { Dividend Yield }=\frac{\text { Proventos Pagos no Ano }}{\text { Último Preço de Fechamento no Ano }}
$$

Onde, os Proventos Pagos no Ano equivalem ao montante de dividendos e juros sobre o capital próprio pagos no ano, também ajustados pelo software, assim não provocando discrepâncias.

Além das variáveis retorno e dividend yield, foram selecionadas algumas variáveis de controle, também obtidas no banco de dados do software Economática, conforme pode ser observado a seguir:

a) $R O A\left(\right.$ Return On Assets) $=\frac{\text { Lucro Líquido }}{\text { Ativo }}$

b) Índice Preço / VPA (Valor Patrimonial por Ação) $=\frac{\text { Último Preço de Fechamento no Ano X }}{\frac{\text { Patrimônio Líquido }}{\text { Quantidade de Ações }}}$

c) Índice Dívida / PL (Patrimônio Líquido) $=\frac{\text { Dívida Total Bruta }}{\text { Patrimônio Líquido }}$

Todos os dados obtidos foram organizados e tabulados em uma planilha do Microsoft Office Excel 2003, assim servindo de banco de dados para se aplicar as técnicas de análise de dados.

Primeiramente, para se explorar a relação entre a distribuição de dividendos e de juros sobre o capital próprio com a valorização do preço das ações, bem como a evolução das variáveis, foi realizada a técnica multivariada de análise de correspondência (Anacor), por meio da utilização do software estatístico SPSS 15. 
Segundo Fávero et al. (2009), a análise de correspondência é uma técnica exploratória que trata da distribuição de frequências resultantes de duas ou mais variáveis qualitativas, buscando explicitar a associação entre suas categorias por meio de mapas perceptuais. Esta técnica fornece uma poderosa ferramenta para identificar relações entre objetos e atributos em um espaço multidimensional, mas é importante ressaltar que, por se tratar de uma técnica exploratória, seus resultados não podem ser generalizados para observações não pertencentes à amostra utilizada pelo pesquisador.

Nesta pesquisa, será utilizada a análise de correspondência em painel, que, segundo Lima (2007, p.62), "é a junção de todas as cross-sections em todos os anos, como se fosse um ano só. Muito parecido com o pooling da regressão".

Para utilizar a técnica de análise de correspondência, os dados foram divididos em quartis para definir o grau de retorno e o grau de dividend yield apresentados pelas empresas, conforme a Tabela 1.

\section{Tabela 1: Quartis das Variáveis}

\begin{tabular}{|c|c|c|}
\hline Quartil & Retorno & Dividend Yield \\
\hline 0 & $-0,9778$ & 0,0000 \\
\hline 1 & $-0,2601$ & 0,0246 \\
\hline 2 & 0,0454 & 0,0472 \\
\hline 3 & 0,4953 & 0,0877 \\
\hline 4 & $1.073,9554$ & 2,3970 \\
\hline
\end{tabular}

Com isso, as empresas receberam notas, de 1 a 4, de acordo com o intervalo de dados divididos pelos quartis. Para o retorno das ações, a categorização é a seguinte: de $-0,9778$ até o valor de 0,2601, nota 1; acima 0,2601 até o valor de 0,0454 , nota 2 ; acima de 0,0454 até o valor de 0,4953 , nota 3 ; e, por último, de 0,4953 até o valor de 1073,9554, nota 4. Assim, o grau de retorno das ações é: Grau 1 - Muito Baixo; Grau 2 - Baixo; Grau 3 - Médio; Grau 4 - Alto.

Já para o dividend yield das ações, a categorização é: de 0,0000 até o valor de 0,0246 , nota 1 ; acima 0,0246 até o valor de 0,0472 , nota 2 ; acima de 0,0472 até o valor de 0,0877 , nota 3 ; e, por último, de 0,0877 até o valor de 2,3970, nota 4. Assim, o grau de dividend yield das ações é: Grau 1 - Muito Baixo; Grau 2 - Baixo; Grau 3 - Médio; Grau 4 - Alto.

Além da utilização das variáveis retorno e dividend yield, também foi utilizada a variável ano na técnica de análise de correspondência. Para facilitar a visualização do mapa perceptual, os anos foram divididos nos seguintes grupos: Grupo 1 - de 1995 a 1999; Grupo 2 - de 2000 a 2003; Grupo 3 - de 2004 a 2007; Grupo 4 - somente o ano 2008. O Grupo 4 contempla apenas o ano de 2008, ano marcado pelo início da crise financeira, a fim de se explorar o efeito da crise nas variáveis retorno e dividend yield.

Após a análise de correspondência, foi utilizada a abordagem de análise de dados em painel através do software Eviews 6, onde a análise de regressão pelo método de Mínimos Quadrados Ordinários (MQO) foi efetuada para estimação da relação de causa e efeito entre as variáveis estabelecidas, sendo desenvolvida para a determinação de aceitação ou rejeição da hipótese formulada.

Conforme Fávero et al. (2009), a análise de dados em painel elabora um "mix" das abordagens cross-section (dados em corte ou seção transversal) e série temporal, em que diversas observações são monitoradas não em apenas um único instante de tempo, como dia, mês ou ano (cross-section), mas ao longo de vários períodos de tempo. Dessa forma, na análise de dados em painel ocorre a multiplicação do número de cross-section pela quantidade de períodos, o que gera a dinâmica intertemporal, que representa o "mix" entre as cross-section e a série temporal.

Ainda segundo Fávero et al. (2009, p. 382),

A análise de dados em painel possui três abordagens mais comuns: pooled independent cross-sections (ou POLS - pooled ordinary least squares), efeitos fixos e efeitos aleatórios. 
Conforme Fávero et al. (2009), um modelo POLS representa uma regressão em sua forma mais convencional, ou seja, apresenta o intercepto e os parâmetros das variáveis para todas as variáveis ao longo de todo o período em análise. Pressupõe-se, neste modelo, que o coeficiente angular da variável explicativa é idêntico para todas as observações ao longo do tempo, ou seja, não leva em consideração a natureza de cada cross-section estudada. O modelo de efeitos fixos, por outro lado, considera essas alterações nas cross-sections ao longo do tempo. Para permitir essas alterações onde o intercepto varia entre as observações, pode-se fazê-lo simplesmente pela inserção de variáveis dummy de intercepto diferencial. Como a inclusão de variáveis representativas pode significar a existência de algum desconhecimento sobre o modelo em questão, é natural que essa falta de informação seja representada por meio do termo de perturbação. Assim, é possível que os termos de erro possam estar correlacionados ao longo do tempo e das observações. O modelo de efeitos aleatórios tem por objetivo captar esse fenômeno.

\section{RESULTADOS OBTIDOS E ANÁLISES}

Após a categorização das variáveis, conforme explicitado na metodologia da pesquisa, foi realizada a análise de correspondência.

Antes de realizar a análise de correspondência entre as variáveis retorno e dividend yield, é necessário realizar o teste Qui-quadrado, que visa verificar se existe associação entre as variáveis, buscando analisar se há indícios que possam levar à rejeição da hipótese nula de independência entre elas. Tendo em vista que o valor do teste Qui-quadrado resulta em um $p$-value de 0,0000 , sendo menor que o nível de significância de 0,05 , pode-se aplicar a análise de correspondência. A seguir, é apresentado o mapa perceptual entre as variáveis retorno e dividend yield:

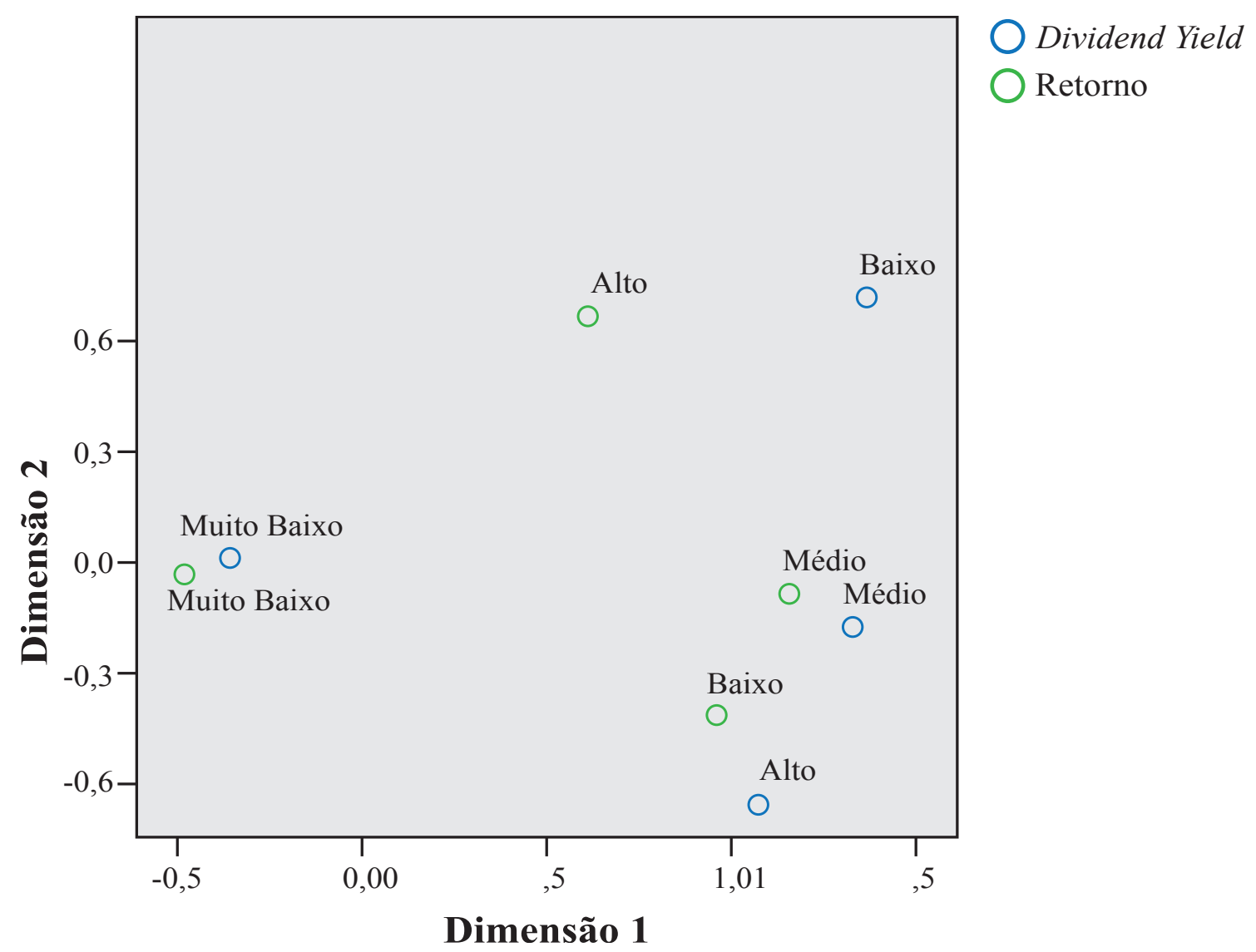

Ilustração 1: Mapa perceptual entre Retorno e Dividend Yield 
Com base no mapa perceptual mostrado na Ilustração 1, é possível verificar que existem algumas associações entre o retorno das ações e o dividend yield. O mapa indica que as ações que apresentam dividend yield muito baixo também apresentam o retorno muito baixo. Também pode ser observado que as ações que apresentam dividend yield médio também apresentam o retorno médio. Outra associação que pode ser feita é entre as ações com alto dividend yield e as ações com baixo retorno, pois estão próximas no mapa. Já as ações com baixo dividend yield demonstram estar mais próximas das ações com alto retorno.

Buscando analisar a evolução do retorno das ações ao longo dos anos, foi realizada a análise de correspondência entre as variáveis retorno e ano e, conforme a aplicação do teste Qui-quadrado, obteve-se um p-value de 0,0000 a um nível de significância de 0,05. Dessa forma, existe associação das variáveis, conforme apresentado no mapa perceptual abaixo:

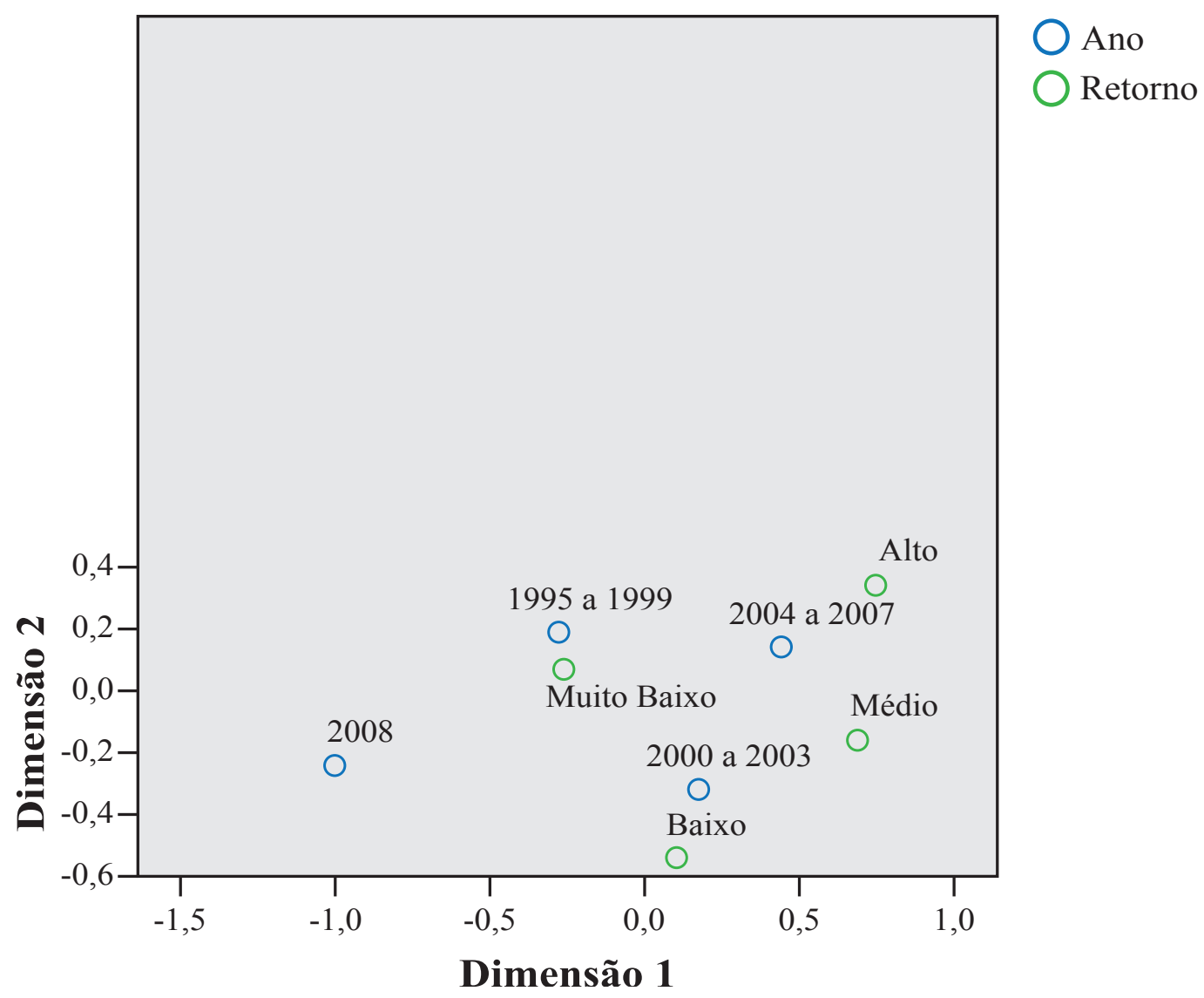

\section{Ilustração 2: Mapa perceptual entre Retorno e Ano}

No mapa perceptual, percebe-se o aumento do retorno das ações ao longo dos anos, exceto no ano de 2008, quando se teve o início da crise financeira, e o retorno deste ano aproximou-se da categoria muito baixo. Pode-se observar que no período de 1995 a 1999 as ações obtiveram retorno muito baixo; já no período de 2000 a 2003, o retorno se aproxima ao nível baixo, e do ano de 2004 a 2007 o retorno das ações apresentam retorno alto, revelando o forte crescimento do mercado de capitais brasileiro nesse período.

Neste trabalho também se buscou analisar a evolução do dividend yield das ações ao longo dos anos. Assim foi realizada a análise de correspondência entre as variáveis dividend yield e ano, obtendo-se para o teste Qui-quadrado a um nível de significância de 0,05 um $p$-value de 0,0000. Dessa forma, também existe associação entre as variáveis dividend yield e ano, conforme é apresentado no mapa perceptual a seguir: 


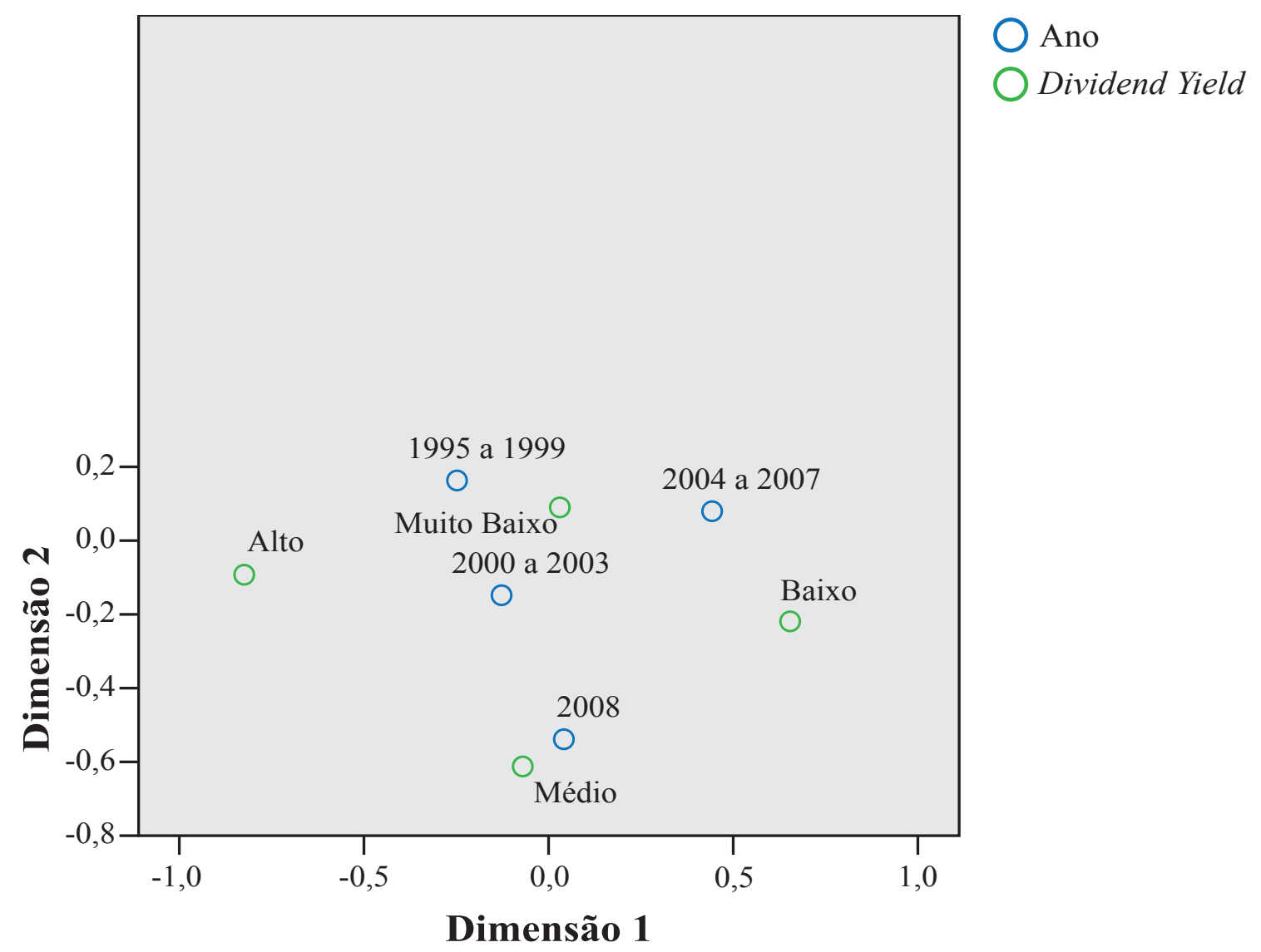

\section{Ilustração 3: Mapa perceptual entre Dividend Yield e Ano}

A partir da relação percebida no mapa perceptual, pode-se concluir que, no período de 1995 a 2003, o dividend yield das ações foi muito baixo e, no período de 2004 a 2007, o dividend yield das ações se manteve próximo dos níveis muito baixo e baixo. Já no ano de 2008, o dividend yield está muito próximo do nível médio.

Para confirmar as análises de correspondência efetuadas, sugere-se a análise de regressão com dados em painel. Inicialmente, alguns testes foram utilizados para a definição do melhor modelo de dados em painel (POLS, efeitos fixos ou efeitos aleatórios). Conforme Fávero et al. (2009), entre o POLS e o modelo de efeitos fixos, utiliza-se o teste de Chow, que, segundo Fávero et al. (2009), as hipóteses são:

$\mathbf{H}_{0}:$ os interceptos são iguais para todas as cross-sections (POLS).

$\mathbf{H}_{\mathbf{1}}$ : os interceptos são diferentes para todas as cross-sections (efeitos fixos).

Por meio do resultado do teste de Chow, foi possível verificar que houve rejeição da hipótese nula de adequação do modelo POLS para a regressão realizada, e, portanto, o modelo escolhido foi o modelo de efeitos fixos.

Na sequência, foi aplicado o teste de Hausman (1978), que, segundo Fávero et al. (2009), permite escolher entre o modelo de efeitos fixos e o modelo de efeitos aleatórios, a partir das seguintes hipóteses:

$\mathbf{H}_{0}$ : modelo de correção dos erros é adequado (efeitos aleatórios).

$\mathbf{H}_{1}$ : modelo de correção dos erros não é adequado (efeitos fixos).

O resultado do teste de Hausman mostra que houve rejeição da hipótese nula para a regressão, e, portanto, o modelo de correção de erros foi rejeitado. O efeito fixo é o que deve ser utilizado. 
Após a definição do melhor modelo (efeitos fixos), foi realizada a regressão pelo método de mínimos quadrados ordinários. Dessa forma, têm-se os principais resultados na Tabela 2.

Tabela 2: Resultados da Regressão com Efeitos Fixos

\begin{tabular}{|c|c|c|c|c|}
\hline & Coeficiente & Erro Padrão & Estatística t & Prob. \\
\hline $\mathrm{C}$ & 0,1690 & 0,0408 & 4,1384 & 0,0000 \\
\hline Dividend Yield & $-0,7658$ & 0,1649 & $-4,6440$ & 0,0000 \\
\hline $\mathrm{ROA}$ & 0,8801 & 0,2501 & 3,5192 & 0,0004 \\
\hline Preço/VPA & 0,0828 & 0,0237 & 3,4997 & 0,0005 \\
\hline \multirow[t]{6}{*}{ Dívida/PL } & $-0,0003$ & 0,0001 & $-2,8080$ & 0,0050 \\
\hline & \multicolumn{2}{|l|}{ R Quadrado } & 0,4755 & \\
\hline & \multicolumn{2}{|c|}{ R Quadrado Ajustado } & 0,3352 & \\
\hline & \multicolumn{2}{|l|}{ Estatística F } & 3,3894 & \\
\hline & \multicolumn{2}{|c|}{ Prob. (Estatística F) } & 0,0000 & \\
\hline & \multicolumn{2}{|c|}{ Estatística Durbin-Watson } & 2,4532 & \\
\hline
\end{tabular}

A Estatística F apresenta o resultado da significância do modelo proposto e, por meio do Prob. (Estatística F), cujo valor é igual a 0,0000 , valor menor que 0,05 , é possível se rejeitar a hipótese nula de não significância da regressão, ou seja, a regressão mostra-se significativa, considerando um nível de confiança de $95 \%$.

Por meio da análise da Estatística t de cada parâmetro, é possível afirmar que a constante $(\mathrm{C}-$ intercepto) e as variáveis Dividend Yield, ROA, Preço/VPA e Dívida/PL são significativas, uma vez que apresentam $p$-value menor que o nível de significância de 0,05 .

Em relação aos pressupostos do modelo de regressão, o teste de normalidade para os resíduos não rejeitou a hipótese nula de normalidade, pelo teste de Jarque-Bera. Pelo teste de Durbin-Watson, é possível observar que o modelo não apresenta problemas de autocorrelação serial dos resíduos, pois seu valor 2,4532 está próximo de 2. Por meio da utilização da correção de White (regressão robusta), eventuais problemas de heterocedasticidade foram corrigidos, dessa forma fornecendo estimadores mais consistentes e não viesados.

Através do R Quadrado, pode-se verificar que a importância, ou o poder explicativo do modelo como um todo é de $47,55 \%$, ou seja, $47,55 \%$ da variação do Retorno é explicada pela variação do Dividend Yield, ROA, Preço/VPA e Dívida/PL.

A equação do modelo é:

$$
\text { Retorno }=0,1690-0,7658 . \quad \begin{gathered}
\text { Dividend } \\
\text { Yield }
\end{gathered}+0,8801 . \mathrm{ROA}+0,828 . \frac{\text { Preço }}{V P A}-0,0003 . \frac{\text { Dívida }}{P L}+\text { erro }
$$

Por meio da interpretação do coeficiente angular da equação, é possível observar que existe uma relação inversa entre a variável Retorno e a variável Dividend Yield, o que representa uma grande importância para este estudo.

\section{CONCLUSÕES}

O objetivo geral desta pesquisa foi analisar a relação entre a distribuição de dividendos e juros sobre o capital próprio e o retorno das ações, respondendo ao seguinte problema de pesquisa: "Existe relação entre a distribuição de dividendos e de juros sobre o capital próprio com o retorno das ações?” 
Para responder o problema de pesquisa, inicialmente, procurou-se analisar a relação das variáveis retorno das ações e distribuição de dividendos e de juros sobre capital próprio. Por meio do uso da técnica multivariada de análise de correspondência em painel, foi possível observar que existe relação entre as variáveis, destacando-se que as ações com distribuição de dividendos e juros sobre capital próprio classificada como baixo apresentam retorno alto; já as ações que apresentam alta distribuição de dividendos e juros sobre capital próprio apresentam baixo retorno.

Neste estudo, avaliou-se também a evolução do retorno das ações e da distribuição de dividendos e de juros sobre capital próprio ao longo dos anos. Por meio da utilização da técnica multivariada de análise de correspondência em painel, foi possível observar que houve aumento do retorno das ações no decorrer dos anos estudados, com exceção ao de 2008, quando se teve o início da crise financeira. Em relação à distribuição de dividendos e de juros sobre capital próprio, também houve aumento no decorrer dos anos, no período que compreende os anos de 2004 a 2007, cujo retorno das ações foi alto e a distribuição de dividendos e juros sobre o capital próprio foi baixa. Já em 2008, o retorno foi muito baixo, e a distribuição de dividendos e juros sobre o capital próprio foi média.

Para confirmar as conclusões da análise exploratória, além de investigar a dependência entre a variável retorno das ações e a variável distribuição de dividendos e de juros sobre capital próprio, foi utilizada a técnica econométrica de análise de regressão em painel. Por meio da regressão com efeitos fixos pelo método de mínimos quadrados ordinários, foi possível aceitar a hipótese formulada de que existe relação entre a distribuição de dividendos e de juros sobre o capital próprio com o retorno das ações, já que o modelo é significante, e assim foi possível responder o problema de pesquisa.

O grau de explicação da regressão foi de aproximadamente $47,55 \%$, ou seja, $47,55 \%$ da variação do retorno das ações é explicada pela variação da distribuição de dividendos e juros sobre o capital próprio, bem como das variáveis de controle ROA, Índice Preço/VPA e Índice Dívida/PL.

Um dos resultados mais importantes deste estudo é que a distribuição de dividendos e juros sobre o capital próprio apresenta uma relação inversa com o retorno das ações. Assim, corroborando a análise exploratória, ações com maior distribuição de dividendos e juros sobre o capital próprio apresentam menor retorno.

Apesar de as conclusões apresentadas serem relevantes, devem-se levar em consideração algumas limitações da pesquisa. As conclusões deste estudo ficam restritas à amostra, às técnicas multivariadas e econométricas utilizadas e aos modelos desenvolvidos, podendo, como sugestões para novas pesquisas, se utilizar de outras técnicas estatísticas, outros modelos e variáveis para, até mesmo, fazer comparações ao estudo apresentado.

\section{REFERÊNCIAS:}

ASSAF NETO, Alexandre. Finanças corporativas e valor. São Paulo: Atlas, 2003.

BRIGHAM, Eugene F., GAPENSKI, Louis C. e EHRHARDT, Michael C. Administração financeira: teoria e prática. Tradução Alexandre Loureiro Guimarães Alcântara e José Nicolas Albuja Salazar. São Paulo: Atlas, 2001.

BRUNI, A. L.; FAMÁ, R.; FIRMINO, A.; GAMA, A.; O anúncio da distribuição de dividendos e seu efeito sobre os preços das ações: um estudo empírico no Brasil. In: III Congresso USP de Controladoria e Contabilidade (Faculdade de Economia, Administração e Contabilidade da Universidade de São Paulo), 2003, São Paulo. Anais...São Paulo: USP, 2003. p.1-20.

BUENO, A. F. B. Análise empírica do dividend yield das ações brasileiras. 2000. 0 f. Dissertação (Mestrado em Controladoria e Contabilidade) - Faculdade de Economia, Administração e Contabilidade, Universidade de São Paulo, 2000. 
CORREIA, L.; AMARAL, H. F. O impacto da política de dividendos sobre a rentabilidade de títulos negociados na BOVESPA no período de 1994 a 2000. In: XXVI Enanpad, 2002, Salvador. Anais... Salvador: XXVI Enanpad, 2002. CD-ROM.

FÁVERO, L. P. et al. Análise de dados: modelagem multivariada para tomada de decisões. $1^{\mathrm{a}}$ edição. Rio de Janeiro: Elsevier, 2009.

LIMA, A. V.; PAIVA, J. W. A influência da tributação e dos juros sobre o capital próprio na política de dividendos das companhias brasileiras. In: I Encontro Brasileiro de Finanças, 2001, São Paulo. Anais... São Paulo: I Encontro Brasileiro de Finanças, 2001. CD-ROM.

LIMA, Gerlando Augusto Sampaio Franco. Utilização da teoria da divulgação para avaliação da relação do nível de disclosure com o custo da dívida das empresas brasileiras. 2007. 0 f. Tese (Doutorado em Controladoria e Contabilidade) - Faculdade de Economia, Administração e Contabilidade, Universidade de São Paulo, 2007.

LIMA, I. S.; FREIRE, H. V. L. O comportamento dos dividendos versus lucros anormais. In: XXVII Enanpad, 2003, São Paulo. Anais... São Paulo: XXVII Enanpad, 2003. CD-ROM.

NOVIS NETO, J. A.; SAITO, R. Dividend yield e persistência de retornos anormais das ações: evidência do mercado brasileiro. In: XXVI Enanpad, 2002, Salvador. Anais... Salvador: XXVI Enanpad, 2002. CD-ROM.

LOPES, Alexsandro Broedel.; MARTINS, Eliseu. Teoria da contabilidade: uma nova abordagem. São Paulo: Atlas, 2005.

MARTINS, Gilberto de Andrade. Manual para elaboração de monografias e dissertações. São Paulo: Atlas, 2000.

NOSSA, S. N.; NOSSA, V.; TEIXEIRA, A. J. C. As empresas que distribuem dividendos são mais eficientes? In: Congresso USP de Controladoria e Contabilidade, 7, (Faculdade de Economia, Administração e Contabilidade da Universidade de São Paulo), 2007, São Paulo. Anais... São Paulo: USP, 2007. CD-ROM.

HEINEBERG, R.; PROCIANOY, J. L. Aspectos determinantes do pagamento de proventos em dinheiro das empresas com ações negociadas na BOVESPA. In: XXVII Enanpad, 2003, São Paulo. Anais... São Paulo: XXVII Enanpad, 2003. CD-ROM.

SANTANA, L. Relação entre dividend yield e retorno das ações abordando aspectos determinantes da política de dividendos: um estudo empírico em empresas com ações negociadas na BOVESPA. 2006. 82 f. Dissertação (Mestrado em Ciências Contábeis) - Fundação Instituto Capixaba de Pesquisas em Contabilidade, Economia e Finanças, Vitória, 2006. 